\title{
DERECHO DE AUTOR Y CULTURA \\ POPULAR TRADICIONAL \\ EN AMÉRICA LATINA Y EL CARIBE
}

ÓSCAR ALbERTo PÉREZ PEÑA*

\section{INTRODUCCIÓN}

El tema de la protección jurídica de la cultura popular tradicional ha sido motivo de preocupación desde hace varias décadas y ha estado en el centro de los trabajos legislativos de organizaciones internacionales como la Organización de las Naciones Unidas para la Educación, la Ciencia y la Cultura (Unesco) y la Organización Mundial de la Propiedad Intelectual (ompI). Estas organizaciones han intentado encontrar los mecanismos ideales para su protección, pero aun en la actualidad no se ha logrado un consenso en este orden ni en el teórico, particularmente en aspectos como su definición, objeto, titularidad de los derechos que sobre ella se persigue obtener y la forma más adecuada para lograrlo.

La legislación dirigida a la protección del patrimonio cultural, las normas de la propiedad industrial, del derecho de autor y derechos conexos, o, más recientemente, normas sui generis con un tipo de protección diferente que tutela aspectos de propiedad intelectual, son algunas de las opciones más conocidas. En cualquiera de los casos, no es un tema acabado.

La vía que brinda el sistema de derecho de autor es aceptada y reconocida y ha permitido que los individuos, y por ende las comunidades en cuyo seno se producen creaciones intelectuales, sean protegidos ante el desenfreno por el expolio de las transnacionales del ocio y el entretenimiento ${ }^{1}$. Las facultades reconocidas

\footnotetext{
* Doctor en Ciencias Jurídicas (PhD), profesor de la Facultad de Jurisprudencia de la Universidad Internacional del Ecuador (UIDE) y de la Facultad de Derecho de la Universidad Metropolitana (UMET). Contacto: ppderechoautor@gmail.com; operezpe@uide.edu.ec; operez@umet.edu.ec Fecha de recepción: 6 de febrero de 2018. Fecha de aceptación: 18 de mayo de 2018. Para citar el artículo: Pérez Peña, Ó. A. "Derecho de autor y cultura popular tradicional en América Latina y el Caribe”, Revista La Propiedad Inmaterial n. ${ }^{\circ}$ 25, Universidad Externado de Colombia, enero-junio 2018, pp. 27-48. Dor: https://doi. org/10.18601/16571959.n25.02

1 Evidencias de esta situación la constituyen los casos Yumbulul v. Reserve Bank of Australia y Milpurruru v. Indofurn Pty Ltd. En el primero se demostró el conflicto fundamental entre el entendimiento aborigen de los derechos en las obras de arte y la ley de derecho de autor, hallándose sin lugar la pretensión del autor en el proceso pues no
} 
a los autores permiten la protección de estas obras y al mismo tiempo propician su reproducción, comunicación pública y transformación de forma controlada, contribuyendo a su revitalización y desarrollo.

Numerosos países africanos y latinoamericanos han acogido en sus legislaciones de derecho de autor la protección a las obras de la cultura popular tradicional. En este caso se ha dirigido la protección hacia las obras que no poseen un autor identificado, pero también se ha reconocido la necesidad de tutelar las derivadas y aquellas que, realizadas con técnicas tradicionales, merecen tal tratamiento.

Como el tema está en constante análisis a nivel internacional, su conocimiento todavía es limitado y por consiguiente su aplicación práctica se comporta de igual forma.

La escasa existencia de estudios jurídicos profundos sobre la materia en el orden latinoamericano, contribuye a la imprecisión de los términos que se utilizan indistintamente o que son acuñados en la práctica cultural y legal latinoamericana ${ }^{2}$. Por otro lado, se aprecia omisión en cuanto a la realización de un estudio comparado de legislación en la materia respecto a su definición, objeto e instituciones jurídicas en su tratamiento.

Cuando se utiliza como referente la legislación de derecho de autor de América Latina y el Caribe, se hace teniendo en cuenta que esta área ha sido una de las más prolíficas en riqueza y diversidad cultural, en la evolución y desarrollo de las culturas populares tradicionales, así como en el orden normativo, pues ya desde

pudo probar que no había licenciado su derecho de reproducción. Había concedido la autorización para la reproducción, pero fue criticado y repudiado por su comunidad una vez que se hizo pública la utilización, y fue conminado a iniciar el proceso judicial. En el segundo, se reprodujeron (sin permiso) total o parcialmente obras muy conocidas de artistas indígenas sobre la historia de la creación en alfombras; el caso fue ganado por estos bajo la ley de derecho de autor australiana, basándose el tribunal en la existencia de un agravio cultural y espiritual, concediendo daños y prejuicios adicionales de los que se beneficiaría la comunidad en virtud de su ley consuetudinaria. En 1998, Moontide, empresa fabricante de trajes de baño de Nueva Zelanda, negoció el uso del motivo koru con uno de los miembros influyentes de la comunidad local. Parte de los ingresos derivados de las ventas se destinan a la familia (hapu) Pirirakau del pueblo Ngati Ranginui. La utilización de un contrato para este negocio fue en virtud de las leyes de propiedad intelectual. Caso Yumbulul v. Reserve Bank of Australia, (1991) 21 I.P.R. 481, 490 (Austl.), citado por Haight Farley, Christine, "Protecting folklore of indigenous peoples is intellectual property the answer?", Connecticut Law Review, 1997, p. 10, disponible en: http://U.K.Westlaw.com/30.Conn.L.Rev.1 [consultado 15 de marzo de 2017]; Milpurruru vs. Indofurn Pty Ltd., en Janke, Ms. Terri, Minding Culture: Case Studies on Intellectual Property and Traditional Cultural Expressions, World Intellectual Property Organization, Geneva, 2003. wipo Publication n.o 781 (E); y Moontide, en Shand, Peter, "Scenes from the colonial Catwalk, cultural appropiation, Intellectual Property Rights, and fashion", Cultural Analysis, vol. 3, 2002, cit. en Propiedad intelectual y expresiones culturales tradicionales o del folklore, Publicación ompi n.o 913(S), 2005, p. 14.

2 Folklore, cultura popular, expresiones culturales tradicionales, expresiones del folklore, cultura popular tradicional, cultura popular y tradicional, patrimonio cultural inmaterial, patrimonio cultural intangible son términos que se utilizan indistintamente y en todo el sistema institucional cultural y jurídico, en muchos casos sin valorar y precisar sus implicaciones y consecuencias. 
los años setenta ${ }^{3}$ las normas de derecho de autor comenzaron a regular las obras de la cultura popular tradicional.

Hemos tomado las legislaciones de 18 países que representan geográficamente toda el área, pues se incluyen ordenamientos del Caribe y de toda América Latina, así: Bolivia, Brasil, Chile, Colombia, Costa Rica, Cuba, El Salvador, Dominica, Jamaica, República Dominicana, Honduras, Ecuador, Guatemala, México, Panamá, Perú, Uruguay y Venezuela. Esto, con el objetivo de identificar las tendencias en esta protección, y de establecer bases teóricas para su estudio.

La metodología empleada en esta investigación ha tenido en cuenta elementos histórico-sociológicos, culturales y jurídicos a partir de la complejidad y pluridisciplinariedad de su objeto, lo que ha supuesto la combinación de métodos de las ciencias sociales en general y de las ciencias jurídicas; específicamente:

1) el análisis histórico se refleja en el seguimiento a estos temas, estudiados históricamente en la doctrina y la legislación latinoamericana, así como en las posibles causas de ausencia teórica en momentos históricos diferentes.

2) el análisis jurídico comparado adquiere especial significación en la investigación pues se fundamenta en el estudio comparado de legislación realizado sobre la protección jurídica de la cultura popular tradicional en la legislación de derecho de autor de 18 países de América Latina y el Caribe, permitiendo comparar su regulación jurídica y brindando elementos indispensables para identificar tendencias en el ordenamiento jurídico latinoamericano y caribeño desde una perspectiva histórica.

3) mediante el análisis hermenéutico-analítico fue posible analizar las soluciones presentes en la legislación comparada (latinoamericana y caribeña), al contrastar ambos supuestos jurídicos para arribar a conclusiones, así como los diferentes instrumentos normativos internacionales sobre la materia.

Dentro de las técnicas de utilidad para esta investigación se tienen la revisión de documentos y la consulta a expertos ${ }^{4}$. La revisión de documentos se ha realizado

3 La protección jurídica de la cultura popular tradicional dio comienzo en 1973, cuando el gobierno de Bolivia solicitó, en el seno de la ompr, que se añadiera un protocolo a la Convención Universal sobre Derecho de Autor de 1952, con el fin de proteger el folklore. Sin embargo, ya desde antes, la Conferencia de Estocolmo de 1967 para la revisión del Convenio de Berna trató de introducir la protección por derecho de autor para la cultura popular tradicional también a nivel internacional.

$4 \mathrm{La}$ consulta a expertos ha sido realizada en países como Cuba, Argentina, España, Venezuela y Ecuador, lo que ha posibilitado a la vez constatar la viabilidad de la presente investigación. Cfr. Jesús Guanche Pérez, investigador titular de la Fundación Fernando Ortiz y del Instituto de Investigación y Desarrollo de la Cultura Cubana; Virtudes Feliú Herrera, etnóloga, musicóloga, investigadora titular del Centro Nacional de Conservación, Restauración y Museología (CEnCrem); Ernesto Vila González, director general del Centro Nacional de Derecho de Autor (CEnda); Zoraida Fernández Burguet, directora jurídica del Ministerio de Cultura; Marta Moreno Cruz, profesora de Derecho de Autor, Derecho de Propiedad Industrial y Derecho Económico; Nancy de la C. Ojeda Rodríguez, profesora de Derecho de Autor y Derecho Civil de la Universidad de La Habana; y María Amparo Santana Calderín, Beatriz Triana López y Ozara M. Acebal Quesada, abogadas del Bufete Internacional y de Bufetes Colectivos, todos de Cuba. De Argentina: Teodora Zamudio, doctora en Derecho por la Universidad de Buenos Aires; Arq. María de las Nieves Arias Incollá, presidente del Concejo Internacional para la Conservación del Patrimonio (CICOP) y Alicia Lapenta, arquitecta, gestora cultural, investigadora y profesora 
con el objetivo de estudiar el tratamiento que se le da al tema en las legislaciones de los países consultados, así como en la doctrina, y en algunos casos cuyas sentencias fueron estudiadas a partir de los expedientes sometidos a sus respectivas jurisdicciones. Por otra parte, la consulta a expertos ha permitido conocer el estado de la temática en el sector cultural y jurídico, así como la experiencia práctica de antropólogos, sociólogos, especialistas, directivos, asesores jurídicos, abogados, profesores y jueces vinculados a la materia.

\section{EVOLUCIÓN DE LA PROTECCIÓN JURÍDICA. DEFINICIÓN, CONDICIÓN DE OBRA Y AUTORÍA DE LAS OBRAS DE LA CULTURA POPULAR TRADICIONAL}

El abordaje jurídico de la cultura popular tradicional no es nuevo, pero sí relativamente reciente 5 . Aquella ha estado vinculada a la existencia de pueblos o comunidades indígenas que han sido víctimas de procesos de colonización. No obstante, el nacimiento y la correspondiente evolución de la mencionada protección no pueden entenderse limitados a estos procesos, pues también en aquellos países que durante las últimas décadas no han sufrido colonización derivada de conflictos $\operatorname{armados}^{6}$ se han dado y se mantienen amenazas sobre sus culturas, relacionadas con las circunstancias en las que se desarrolla la vida actualmente y con otros procesos como la globalización ${ }^{7}$.

Se han ido estableciendo en el orden jurídico una serie de definiciones ${ }^{8}$ coincidentes en aspectos que han caracterizado históricamente a estas comunidades,

de la Universidad del Centro de la Provincia de Buenos Aires. Por España: Dámaso Javier Vicente Blanco, catedrático de la Facultad de Derecho de la Universidad de Valladolid. Por Venezuela: Omar Vielma, presidente del Instituto Nacional de Patrimonio Cultural de Venezuela, e Isabel Cristina Piña Sierra, directora del área de puesta en uso y valor del patrimonio cultural, de la misma institución venezolana. Por Ecuador: Verónica Morales Ramos, antropóloga, abogada, gestora cultural y profesora de la Universidad Internacional del Ecuador.

5 Wolfrum, Rüdiger, "La protección de los pueblos indígenas en el derecho internacional", Heidelberg Internacional Journal, 59, 1999, pp. 369-382, y "Propuesta de un instrumento internacional para la protección del folklore". Comité Intergubernamental de Derecho de autor. Duodécima reunión de la Organización Mundial de la Propiedad Intelectual. París, diciembre de 1973. IGC/XII/12, disponible en: http://www.wipo.int [consultado el 1 de mayo de 2017].

6 Para un análisis sobre la situación de los pueblos indígenas en el tiempo de la colonización, cfr. Wiessner, Siegfried, "Rights and status of indigenous peoples: A global comparative and international legal analysis", Harvard Human Rights Journal, 12, 1999 , pp. $57-128$

7 López Segrera, Francisco, “Globalización, cultura y desarrollo", en Honda, Revista de la Sociedad Cultural José Martí, n.o 2, año 1, 2000, p. 16.

8 Ejemplos de definiciones en el orden internacional son las recogidas en los siguientes instrumentos normativos: Convención concerniente a los pueblos indígenas y tribales en Países Independientes; la Directiva Operacional 4.20 del Banco Mundial y el concepto del Grupo de Trabajo de Poblaciones Indígenas recogido en el informe del Relator General de Naciones Unidas en 1996. Además, algunos documentos y tratados sobre medio ambiente utilizan el término “indígenas y comunidades locales", como los documentos adoptados en la Cumbre de Río sobre Medioambiente y Desarrollo, así como la Convención sobre Diversidad Biológica y la Convención para combatir la Desertificación. Sobre el análisis de la definición de "pueblos indígenas" cfr. Stoll, Peter-Tobias y Von Hahn, Anja, "Part 
las cuales han sido blanco de ataques y despojo desde tiempos inmemoriales ${ }^{9}$, así como a aquellas otras que en la actualidad intentan preservar sus legados históricos ante situaciones como el comercio internacional, y que de una forma u otra han incidido en su ulterior protección jurídica.

En la actualidad, todas las comunidades están expuestas a un proceso de colonización cultural que viene fundamentalmente del Norte, y también han sentido la necesidad de preservar y proteger sus culturas ante fenómenos como la globalización. Esta, con independencia de elementos positivos, ha tendido a arrasar con las identidades culturales y a convertirlas en world culture, en un proceso de mcdonalización creciente, como reconoce López Segrera ${ }^{10}$, y donde las obras de la cultura popular tradicional han sido recontextualizadas y alteradas sin reconocimiento, por los utilizadores o comerciantes, de su procedencia, así como tampoco de los individuos y grupos que tradicionalmente las han cultivado y desarrollado en algunos casos, estos últimos conocidos como grupos portadores ${ }^{11}$.

De una forma u otra, en ambos casos, tanto las comunidades indígenas como las no reconocidas como tales han sentido la necesidad de proteger su cultura popular tradicional. Es así como ha ido emergiendo una tendencia internacional, esto directamente a través del reconocimiento y protección de las culturas tradicionales y los derechos de los pueblos indígenas.

No obstante este desarrollo, el derecho internacional no ha sido todavía capaz de establecer un régimen uniforme sobre los derechos de los pueblos indígenas ${ }^{12}$, como tampoco sobre los distintos sistemas de protección jurídica relacionados con la cultura popular tradicional; aspecto este último que se evidencia en los esfuerzos realizados por diversas organizaciones internacionales desde hace ya varios años.

Desde el punto de vista internacional la protección jurídica de la cultura popular tradicional dio comienzo en 1973 cuando el gobierno de Bolivia propuso se añadiera

II. Indigenous peoples, indigenous knowledge and indigenous resources in International Law", en Von Lewinski, Silke, Indigenous Heritage and Intellectual Property, Kluwer Law International, The Netherlands, 2004, pp. 5-11.

9 Para un análisis de la situación de los pueblos indígenas en el tiempo de la colonización, cfr. Wiessner, Siegfried, "Rights and status of indigenous peoples: A global comparative and international Legal Analysis", Harvard Human Rights Journal, 12, 1999, pp. 57-128

10 López Segrera, Francisco, "Globalización, cultura y desarrollo", en Honda, Revista de la Sociedad Cultural José Martí, n.o 2, año 1, 2000, p. 16.

11 "Portadores de tradiciones": se denomina así a aquellos grupos e individuos cuyo condicionamiento cultural depende del proceso de formación histórico-social de que forman parte, lo que les permite reflejar y transmitir los valores culturales de las generaciones que les antecedieron. Dentro de estos grupos e individuos se incluye a los practicantes propiamente dichos y a los informantes o testimoniantes de estas tradiciones. Individualmente, es el miembro de una comunidad que reconoce, reproduce, transmite, transforma, crea y forma una cierta cultura en el interior de y para una comunidad. Un portador puede, por añadidura, jugar uno o varios de los siguientes roles: practicante, creador o guardián. Este concepto es manejado por el Glosario de términos de la Unesco. Cfr. Glosario de términos de la Unesco, disponible en: http://www.unesco.org [consultado 1 de mayo de 2017].

12 Wolfrum, Rüdiger, "La protección de los pueblos indígenas en el derecho internacional”, Heidelberg Internacional Journal, 59, 1999, pp. 369-382. 
un Protocolo a la Convención Universal sobre Derecho de Autor, con el fin de proteger el folklore. En 1976, con ayuda de la Unesco y la Organización Mundial de la Propiedad Intelectual (OMPI), un comité de expertos gubernamentales aprobó la Ley Tipo de Túnez, que se refiere a la protección del folklore ${ }^{13}$.

Conjuntamente con la OMPI, en 1982 la Unesco publicó las "Disposiciones tipo para las leyes nacionales sobre la protección de las expresiones del folklore contra la explotación ilícita y otras acciones lesivas" ${ }^{14}$. Este proceso, que dura hasta los días de hoy, ha producido diversos instrumentos jurídicos internacionales y programas en el seno de la Unesco, tales como: la Recomendación sobre la Salvaguardia de la Cultura Tradicional y Popular de 1989; la Convención para la Salvaguardia del Patrimonio Cultural Inmaterial de 2003, o la Convención sobre la Protección y Promoción de la Diversidad de las Expresiones Culturales de 2005, así como el Sistema de Tesoros Humanos Vivos (1994) y la Proclamación de Obras Maestras del Patrimonio Oral e Inmaterial de la Humanidad (1997). La OMPI ha continuado su labor y su Asamblea General, en el año 2000, creó un Comité Intergubernamental sobre la Propiedad Intelectual, Recursos Genéticos, Conocimientos Tradicionales y Folklore que ha llevado a cabo negociaciones con el objetivo de alcanzar un acuerdo sobre un texto (o textos) de un instrumento jurídico internacional (o varios) que asegure(n) la efectiva protección de los conocimientos tradicionales (CC.TT.), las expresiones culturales tradicionales (ECT) y los recursos genéticos (RR.GG.).

Otro grupo de organizaciones internacionales han realizado actividades sobre ciertos aspectos de la cultura popular tradicional en relación con su salvaguardia, entre ellas: la Organización Mundial de la Salud (OMS), la Organización de las Naciones Unidas para la Agricultura y la Alimentación (FAO), la Organización Internacional del Trabajo (OIT), el Programa de las Naciones Unidas para el Medio Ambiente (PNUMA) y la Conferencia de las Naciones Unidas sobre Comercio y Desarrollo (UnCTAD) ${ }^{15}$.

El sistema de derecho de autor y derechos $\operatorname{conexos}^{16}$ es:

13 Lucas-Schloetter, Agnes, "The Tunis Model Law on Copyright (wipo/ Unesco, 1976), Section 4. Folklore”, en Von Lewinsky, Silke, Indigenous heritage and intellectual property. Genetic resources, traditional knowledge and folklore, Kluwer Law International, The Hague, 2004, pp. 340-342.

14 Peréz Peña, Óscar Alberto, "Propiedad intelectual y patrimonio cultural: protección jurídica a la cultura popular tradicional, con especial referencia a Cuba”, Revista Propiedad Intelectual, Mérida (Venezuela), año x, n.o 14, enero-diciembre 2011, p. 217.

15 Ibíd., p. 219. Respecto a la participación de todas estas organizaciones internacionales en la protección de la cultura popular tradicional cfr. el Informe relativo al Estudio Preliminar sobre la "Conveniencia de reglamentar en el ámbito internacional la protección de la cultura tradicional y popular mediante un nuevo instrumento normativo", Organización de las Naciones Unidas para la Educación, la Ciencia y la Cultura, 161. a Reunión, 161 EX/15, París, 16 de mayo de 2001, disponible en: www.unesco.org [consultado el 17 de diciembre de 2009].

16 En la actualidad las legislaciones nacionales de diversos países establecen normas de protección por la vía del derecho de autor a la cultura popular tradicional, incluyendo a Cuba con su Ley n. ${ }^{\circ} 14$ de 1977. Veamos: Argelia: Copyrights and Neighboring 
... un sistema que busca establecer facultades del autor o titulares ante terceros y que, desde hace años, se ha extendido a la cultura popular tradicional, con independencia del valor cultural, mérito o destino que posean sus expresiones, durante un tiempo determinado; transcurrido este, pasan a ser de dominio público y por lo tanto pueden ser utilizadas libremente, pudiendo realizarse reproducciones, comunicaciones públicas y transformaciones, siempre que no se afecten facultades morales ${ }^{17}$.

Esta lógica clásica del derecho de autor es la que permite la utilización, al pasar las obras a dominio público ${ }^{18}$ o antes, bajo la condición de obra derivada ${ }^{19}$, y la creación de nuevos derechos propietarios, como en el caso de que la modificación, con cierto grado de originalidad, genere un nuevo copyright para obras maestras de la cultura popular ${ }^{20}$.

Una modificación del mismo, "como ya lo reflejan propuestas sui generis ${ }^{21}$ que están en acción o que han sido publicadas, buscaría una protección de propiedad

Rights Act, 2003; Bolivia: Leyes de Derecho de Autor, 1992; Burkina Faso: Loi portant protection de la Propriété Littéraire et Artistique, 1999; Chile: Leyes de Derecho de Autor, 1970; Colombia: Leyes de Derecho de Autor, 1982; Costa de Marfil: Law on the Protection of Intellectual Works and the Rights of Authors, Performers and Phonogram and Videogram Producers, 1996; Fiji: Copyright Act, 1999; Ghana: Copyright Act, 2005; Indonesia: Copyright Law, 2002; Lituania: Copyrights and Related Rights, 2003; Macedonia, The former Yugoslav Republic of: Law on Copyrights and Related Rights, 1998; Malawi: Copyright Act, 1989; México: Copyright Act, 1989; Micronesia, Federated States of: Federated States of Micronesia Code: Copyright, Patents \& Trademarks, 2003; Mongolia: Copyright Law of Mongolia, 1993; Marruecos: Copyrights and Neighbouring Rights, 2000; Nigeria: Copyright Act, 1999; Omán: Law on Copyrights and Related Rights, 2000; Papúa Nueva Guinea: Copyright and Neigbouring Rights Act, 2000; Perú: Ley Sobre el Derecho de Autor, 1996; Samoa: Copyright Act, 1988; Senegal: Copyright Act, 1973; Tanzania: Copyright and Neighbouring Rights Act, 1999; Túnez: Loi relative à la Propriété Littéraire et Artistique, 1994; Ucrania: Law on Copyrights and Related Rights, 2001; Reino Unido: Copyright, Designs and Patents Act, 1988; Vanuatu: Copyright and Related Rights Act, 2000. Disponible en: http:/www.wipo.int. htm [consultado el 7 de julio de 2017].

17 Peréz Peña, ob. cit., p. 225.

18 Se utiliza para referirse a las obras culturales tradicionales, cuyos contenidos tiene derecho a utilizar legítimamente cualquier persona cuando han expirado las facultades patrimoniales de derecho de autor, una vez transcurrido el término de duración y vigencia de las mismas. Las facultades patrimoniales del autor tienen duración limitada según las leyes y la doctrina de derecho de autor, siendo el plazo mínimo establecido por el Convenio de Berna, luego del fallecimiento del autor, de 50 años. En muchos casos han llegado a prolongarse hasta 70 años a partir de la muerte del mismo, como ocurre en la Unión Europea, Perú y Brasil, y en otros aún más, como en México, donde se ha establecido en 100 años post mortem.

19 Son obras derivadas, para el derecho de autor, las que se basan en una obra preexistente. Se consideran como tales las adaptaciones, traducciones, actualizaciones, antologías, resúmenes, extractos y cualquier transformación de una obra anterior de la que resulta una obra diferente. Ver Lipszyc, Delia, Derecho de autor $y$ derechos conexos, Unesco, Cerlalc, Zavalía y Editorial “Félix Varela”, La Habana, 1998, p. 111.

20 Garrote Fernández-Díez, I., "El patrimonio inmaterial y los derechos de propiedad intelectual", en Patrimonio Cultural de España, n.o 0, 2009, pp. 111-132

21 Así el Régimen Especial de Propiedad Intelectual sobre los Derechos Colectivos de los Pueblos Indígenas, para la Protección y Defensa de su Identidad Cultural y de sus Conocimientos Tradicionales de 2000, de Panamá, y su correspondiente Decreto Ejecutivo de 2001. O el Marco Regional para el Pacífico relativo a la protección de los conocimientos tradicionales y las expresiones de la cultura de 2002. Otros ejemplos son la Ley 
intelectual directa reconociendo derechos comunitarios o colectivos a las comunidades portadoras en aquellos casos en que no sea posible identificar autor" ${ }^{22}$, y que dispensa el sistema de derecho de autor sobre las obras anónimas. Protegería a las comunidades ante las distorsiones o mutilaciones que puedan sufrir y que constituyan daños morales o patrimoniales, otorgándoles compensaciones económicas.

La forma o vía de protección jurídica a utilizar, varía en dependencia del tipo de obra ${ }^{23}$ o expresión cultural tradicional, así como de los intereses de autores y de grupos portadores; de ahí que soy del criterio de que, dada la amplitud de creaciones y expresiones que componen la cultura popular tradicional, esta debe ser protegida por diversas vías, entre las cuales el derecho de autor y derechos conexos constituye solo una, que en particular ofrece protección a las obras artísticas y literarias.

El derecho de autor, en el caso de la cultura popular tradicional, protege el conjunto de obras literarias y artísticas creadas por autores no conocidos o que no se identifiquen, que se presuman nacionales del país y se transmitan de generación en generación, de manera que reflejen las expectativas artísticas o literarias tradicionales de una comunidad; así como las obras contemporáneas creadas por autores actuales con técnicas tradicionales, y las obras derivadas con suficiente originalidad que utilizan una obra de la cultura popular tradicional como obra preexistente.

Esta concepción de derechos de autor que rescata el rol de la comunidad y su estrecha relación con las creaciones ya difiere de por sí del sistema clásico autoral, donde el autor debe ser siempre "identificable". Siguiendo esta línea de pensamiento dentro del sistema autoral, en aquellos casos en que determinados miembros identificados dentro de una comunidad creen obras con suficiente originalidad e individualidad, podrían alegar autoría siempre y cuando no afecten regulaciones comunitarias, ya sea como obras de un autor o como obras en colaboración o colectivas, de acuerdo a la expresión de que se trate en cada caso, pues no todas las obras de la cultura popular tradicional reúnen las características de las obras a efectos de la normativa sobre derecho de autor.

sobre los Derechos de los Pueblos Indígenas de 1997, de Filipinas; el Acuerdo de Bangui por el que se crea la Organización Africana de la Propiedad Intelectual (OAPI), revisado en 1999, y la Ley de las Artes y Oficios Indias de 1990, de Estados Unidos (The U.S. Arts and Crafts Act). Cfr. Base de datos de la ompi de textos legislativos de propiedad intelectual, disponible en: http://www.wipo.int.htm [consultado 25 de agosto de 2017].

22 Peréz Peña, ob. cit., p. 225.

23 Es sabido que hay creaciones culturales tradicionales que tienen cabida en más de un sistema de protección de la propiedad intelectual, como en el caso de las artesanías que califican como obras de arte aplicado, que a su vez tienen un aspecto estético u ornamental novedoso, que le interesan en uno u otro sentido tanto al derecho de autor como a la propiedad industrial, respectivamente, llegando incluso a acumular protección por ambas vías en dependencia de la legislación nacional del país en cuestión. Cfr. Carracedo González, Clara Marvilia, "Medios jurídicos para la protección de las artesanías en la legislación cubana de propiedad intelectual: ventajas de la protección acumulada", Documento OMPI-CCI/DA/HAV/01/4, 21 de febrero de 2001, disponible en: www.wipo.int/.../OMPI_CCI.../OMPI_CCI_DA_HAV_01_4_S.pdf [consultado el 27 de febrero de 2017]. 
En consecuencia, estas obras generalmente estarán relacionadas con una comunidad o grupo portador, el cual puede ser también identificado o no. Si bien algunas de ellas pueden ser protegidas como obras anónimas, en caso de que no se conozca su autor por su origen remoto, siguiendo las condiciones acumulativas ${ }^{24}$ del artículo 15 a) del Convenio de Berna y designando una autoridad competente legitimada para defenderlas, se distinguen de las obras anónimas clásicas protegidas tradicionalmente por el derecho de autor, en las que en el momento de divulgarse la obra el autor decide permanecer en el anonimato. Acá se ha perdido el autor en el tiempo o no, y en algunos casos incluso se ha decidido que sea secreta. Si se identifica la comunidad portadora, estaríamos en presencia de una titularidad derivada del derecho de autor sobre la obra originaria, que podría establecerse por presunción de cesión establecida por ley, en cabeza de la comunidad que la ha venido cultivando y a la cual su autor no identificado cedió en su momento. Las normas de derechos conexos puede proteger las expresiones culturales de forma indirecta, sobre todo cuando se realicen interpretaciones o ejecuciones de expresiones en sentido amplio, que no califican como obras por el derecho de autor ${ }^{25}$; así como cuando quedan incorporadas en fonogramas, audiovisuales o en emisiones de radiodifusión. Con independencia de lo anterior, también es insuficiente para la protección de expresiones culturales tradicionales en los casos de aquellas vinculadas a elementos de carácter material, como las artesanías.

En este sistema, los derechos o facultades patrimoniales se gestionan de diversas formas, sin embargo, a nivel internacional se ha estandarizado el modelo de gestión colectiva de las sociedades de autores. Estas sociedades gestionan los derechos derivados de la explotación económica de las obras de sus asociados, donde muchas de ellas son obras derivadas de la cultura popular tradicional. Por consiguiente, sus autores tomaron una obra preexistente sin mediar autorización alguna en muchos casos, y tampoco contraprestación económica por el uso, por encontrarse estas en el dominio público ${ }^{26}$.

En las legislaciones de derecho de autor de América Latina y el Caribe, respecto a la definición escogida, la condición de obra y la autoría de obras asociadas a la cultura popular tradicional, se observa dos tendencias:

24 1) que la obra no esté publicada (editada con el consentimiento del autor, según el artículo 3.3 del propio Convenio), 2) que el autor sea desconocido y 3) que, no obstante ello, pueda presumirse que es nacional. Convenio de Berna para la Protección de las Obras Literarias y Artísticas de 1886 (Acta de París del 24 de julio de 1971), en Propiedad intelectual. Biblioteca de legislación, Aranzandi, 2010, p. 20.

25 Tales como: determinados sonidos, palabras y nombres aislados, ceremonias, rituales y la celebración de prácticas y juegos tradicionales.

26 Cfr. Vicente Blanco, Dámaso Javier, "Protección de la cultura popular y entidades de gestión colectiva: ¿apropiación de bienes comunes y enriquecimiento sin causa?”, Jornadas Internacionales “Arte y Derecho", Azul, Provincia de Buenos Aires, 15 a 18 de noviembre de 2012, sin publicar, p. 18. 
1. Una, en la que no se realiza mención expresa a este tipo de obras ${ }^{27}$, limitándose a su consideración de obras en dominio público y, además, al reconocimiento de la condición de derivadas de estas.

2. Otra, en la que se utiliza la definición de expresiones del folklore, que incluye obras, en varios países, de forma semejante en el contenido del objeto ${ }^{28}$, salvo algunas diferencias ${ }^{29}$. Se coincide generalmente en la autoría, al reconocer

27 Las legislaciones de Brasil, Costa Rica, El Salvador, Honduras, Jamaica y Uruguay presentan, como común denominador, el no hacer mención expresa a este tipo de obras. Venezuela no tiene referencia ninguna en su Ley de Derecho de Autor, pero se diferencia de las anteriores en que utiliza el término "conocimientos tradicionales" en su Constitución. Cfr. Constitución de la República Bolivariana de Venezuela, art. 124: "Se garantiza y protege la propiedad intelectual colectiva de los conocimientos tradicionales e innovaciones de los pueblos indígenas. Toda actividad relacionada con los recursos genéticos y los conocimientos asociados a los mismos perseguirá beneficios colectivos. Se prohíbe el registro de patentes sobre estos recursos y conocimientos ancestrales". Disponible en: http://www.cne.gov.ve/documentos/constitucion00.php [consultado en febrero de 2010]. Cfr. Base de Datos de Leyes Nacionales sobre Derechos de Autor de la Unesco, disponible en: http://portal.unesco.org/culture/es/ev.php-URL_ID=I4076\&URL_DO=DO_TOPIC\&URL_SECTION=201. html [consultada 4 de diciembre de 2017].

28 Perú, Panamá, República Dominicana y Bolivia. Las cinco legislaciones tienen como elemento común que establecen como definición la de expresiones culturales tradicionales, y respecto al contenido coinciden también en que son "producciones de elementos característicos del patrimonio cultural tradicional, constituidas por el conjunto de obras literarias y artísticas, creadas en el territorio nacional, por autores no conocidos o que no se identifiquen, que se presuman nacionales del País, de sus comunidades étnicas y se transmitan de generación en generación, de manera que reflejen las expectativas artísticas o literarias tradicionales de una comunidad". México, es el único país que, aun cuando reconoce que son obras de autor no identificado estrechamente vinculadas con una comunidad, utiliza indistintamente el término "expresiones de culturas populares" y las va citando como expresiones. Cuba refiere que "serán protegidas por esta ley todas aquellas obras folklóricas que han sido transmitidas de generación en generación y que han contribuido a conformar la identidad cultural nacional de manera anónima y colectiva o en cualquier otra forma”. Ley n. ${ }^{\circ}$ 14, de Derecho de Autor, de 1977, art. 26.

29 Respecto a las diferencias, Dominica no se refiere expresamente a "obras", aunque utiliza la misma definición. Venezuela emplea el término "conocimientos tradicionales" en su Constitución, y Ecuador lo hace en su actual legislación de propiedad intelectual, de 2016. Colombia y Chile tienen como elemento semejante que no se refieren a autores no identificados. Guatemala se diferencia de todas en que solo se refiere a los intérpretes o ejecutantes que las interpreten o ejecuten, separándolas expresamente de las obras al considerarlas expresiones, y estableciendo además que pertenecen al patrimonio cultural, lo que limita su alcance a derechos conexos y al sistema de patrimonio cultural. Cfr. Ley de Derecho de Autor y Derechos Conexos de Guatemala, de 21 de mayo de 1998, art. 4: "Para efectos de esta ley se entiende por: Artista intérprete o ejecutante: Todo actor, cantante, músico, bailarín u otra persona que represente un papel, cante, recite, declame, interprete o ejecute en cualquier forma obras literarias o artísticas o expresiones de folclore". Cfr. art. 14 ibíd.: "Las expresiones de folclore pertenecen al patrimonio cultural del país y serán objeto de una legislación específica”. Ecuador, por su parte, refiere como conocimientos tradicionales: "Son todos aquellos conocimientos colectivos, tales como prácticas, métodos, experiencias, capacidades, signos y símbolos propios de pueblos, nacionalidades y comunidades que forman parte de su acervo cultural y han sido desarrollados, actualizados y transmitidos de generación en generación. Son conocimientos tradicionales, entre otros, los saberes ancestrales y locales, el componente intangible asociado a los recursos genéticos y las expresiones culturales tradicionales. Estos conocimientos tradicionales pueden referirse a aspectos ecológicos, climáticos, agrícolas, medicinales, artísticos, artesanales, pesqueros, de caza, entre otros, mismos que han sido desarrollados a partir de la estrecha relación de los seres humanos con el territorio y la naturaleza": Código Orgánico de la Economía Social de los Conocimientos, Creatividad 
que pueden ser de autores no identificados, percibiéndose la estrecha relación con la comunidad de origen.

A tenor de las anteriores consideraciones, el derecho de autor, en el caso de la cultura popular tradicional, protege las expresiones culturales tradicionales constituidas por el conjunto de obras literarias y artísticas, creadas por autores no conocidos o que no se identifiquen, autores que se presuman nacionales del país, y que se transmitan de generación en generación, de manera que reflejen las expectativas artísticas o literarias tradicionales de una comunidad; así como las obras contemporáneas creadas por autores actuales con técnicas tradicionales, y las obras derivadas con suficiente originalidad que utilizan una expresión cultural tradicional como obra preexistente. En aquellos casos en que determinados miembros identificados dentro de una comunidad creen obras con suficiente originalidad e individualidad, los mismos podrían alegar autoría siempre y cuando no afecten regulaciones comunitarias, ya sea como obras de autoría individual o como obras en colaboración o colectivas, de acuerdo a la expresión de que se trate en cada caso; pues no todas las obras de la cultura popular tradicional reúnen las características de las obras a efectos de la normativa sobre derecho de autor. Estas obras generalmente estarán relacionadas con una comunidad o grupo portador, el cual puede ser también identificado o no.

Si bien algunas de ellas pueden ser protegidas como obras anónimas, en caso de que no se conozca su autor por su origen remoto, siguiendo las condiciones acumulativas del artículo 15 a) del Convenio de Berna y designando una autoridad competente legitimada para defenderlas, se distinguen de las obras anónimas clásicas protegidas tradicionalmente por el derecho de autor, en las que al momento de divulgarse la obra el autor así lo decidió. Acá se ha perdido el autor en el tiempo o no, y en algunos casos incluso, se ha decidido que sea secreta. Si se identifica la comunidad portadora, estaríamos en presencia de una titularidad derivada del derecho de autor sobre la obra originaria, que podría establecerse por presunción de cesión establecida por ley, en cabeza de la comunidad que la ha venido cultivando y a la cual su autor no identificado cedió en su momento.

Esta presunción de cesión, de ser instituida en ley, podría ser considerada como fórmula para la protección de estas obras si se identifica esa comunidad o grupo que por tradición ha cultivado la manifestación. En ese caso, ella debe ser la titular del derecho. En caso de no identificarse, lo que sucede en la mayoría de los supuestos, pudiera establecerse la atribución de la titularidad a la comunidad en sentido general, esto es, al país. Es decir, al conjunto de ciudadanos nacionales que conforman nuestra sociedad y que también han preservado dicha obra, lo que sería posible a partir de la autorización otorgada a una autoridad competente, tal como aparece en uno de los requisitos previstos en el Convenio de Berna, y que estaría legitimada para velar por el cumplimiento del derecho de autor, sobre 
todo respecto a las facultades de paternidad e integridad de la obra, en caso de que hayan pasado a ser consideradas de dominio público o en el resto, respecto también a las patrimoniales.

\section{OBRAS DERIVADAS}

En cuanto a la legislación de los países de América Latina escogidos para este estudio, se aprecia que: 1) todos reconocen la protección a las obras derivadas en sentido general, e incluyen en estas, no de forma expresa, las obras de la cultura popular tradicional; 2) algunos países ${ }^{30}$ las refieren expresamente al considerar que son protegidas por el derecho de autor solo las derivadas de estas obras, diferenciándolas de las obras tradicionales originarias en las que la comunidad portadora se ha identificado, por considerarlas objeto de derechos colectivos de propiedad intelectual ${ }^{31} \mathrm{y}$, por ende, reguladas en otras normas.

30 Panamá y Ecuador se diferencian del resto de los países estudiados al particularizar en el tratamiento de las obras derivadas, y a su vez coinciden en este, al establecer que adquieren la protección por derecho de autor solo las obras derivadas, pues las obras tradicionales originarias donde la comunidad portadora se ha identificado son consideradas objeto de derechos colectivos de propiedad intelectual. Cfr. Ley de Derechos de Autor y Derechos Conexos, Ley n. ${ }^{\circ} 64$ de 10 de octubre de 2012, de Panamá, art. 12: "Sin perjuicio de los derechos sobre la obra originaria, son también objeto de protección las traducciones, adaptaciones, transformaciones o arreglos de obras de expresiones del folclor, así como también las antologías o complicaciones de obras diversas y las bases de datos que, por la selección o disposición de las materias, constituyen creaciones personales". Cfr. Código Orgánico de la Economía Social de los Conocimientos, Creatividad e Innovación del Ecuador, de 9 de diciembre de 2016, art. 106: "De las creaciones basadas en las expresiones culturales. Las creaciones o adaptaciones basadas en las tradiciones y prácticas ancestrales, expresadas en grupos de individuos que reflejan las expresiones de las comunas, comunidades, pueblos y nacionalidades indígenas, pueblo afro ecuatoriano y pueblo montubio, su identidad, sus valores transmitidos oralmente, por imitación o por otros medios, ya sea que utilicen lenguaje literario, música, juegos, mitología, rituales, costumbres, artesanías, arquitectura u otras artes, deberán respetar los derechos de las comunidades de conformidad con la normativa internacional, comunitaria y nacional para la protección de las expresiones en contra de su explotación ilícita, así como los principios básicos de los derechos colectivos".

31 Cfr. Ley de Derechos de Autor y Derechos Conexos, Ley n.o 15 de 8 de agosto de 1994, de Panamá, art. 9: "La protección reconocida en la presente Ley no alcanzará a los textos de las leyes, decretos, reglamentos oficiales, tratados públicos, decisiones judiciales y demás actos oficiales; ni a las expresiones genéricas del folclor, noticias del día, ni a los simples hechos y datos". La ley que dirige su protección a las expresiones genéricas es la Ley n. ${ }^{\circ} 20$ de 26 de junio de 2000. Cfr. art. 1: "Esta Ley tiene como finalidad proteger los derechos colectivos de propiedad intelectual y los conocimientos tradicionales de los pueblos indígenas sobre sus creaciones, tales como invenciones, modelos, dibujos y diseños, innovaciones contenidas en las imágenes, figuras, símbolos, gráficos, petroglifos y otros detalles; además, los elementos culturales de su historia, música, arte y expresiones artísticas tradicionales, susceptibles de un uso comercial, a través de un sistema especial de registro, promoción y comercialización de sus derechos, a fin de resaltar los valores socioculturales de las culturas indígenas y hacerles justicia social”. Del Régimen Especial de Propiedad Intelectual sobre los derechos colectivos de los pueblos indígenas, para la protección y defensa de su identidad cultural y de sus conocimientos tradicionales, disponible en: http://www.prodiversitas.bioetica.org/20pan. htm Cfr. Código Orgánico de la Economía Social de los Conocimientos, Creatividad e Innovación de Ecuador, de 9 de diciembre de 2016, art. 512: "Del reconocimiento de los conocimientos tradicionales. De conformidad con lo establecido en la Constitución de 
Así, desde la Ley de Derecho de Autor de Panamá y de Ecuador se enuncia un sistema de protección distinto, sui generis, similar al de las Disposiciones Tipo que analiza la OMPI y que complementa la protección de derecho de autor. En este, la protección de las obras derivadas está sujeta a la autorización ${ }^{32}$ que emita la autoridad competente designada o la comunidad portadora para poder realizarse el uso una vez que la expresión cultural tradicional ha sido registrada como tal (caso Panamá $)^{33}$. Este sistema de normas sui generis ha generado posiciones encontradas

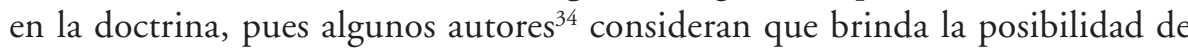
controlar las utilizaciones que se hagan de las expresiones, evitando los atentados a las mismas y obteniendo ingresos para la comunidad donde se originan. Otros autores ${ }^{35}$ plantean que se entorpece la circulación de la cultura con las autorizaciones y el encarecimiento, incluso en los países de origen. Soy del criterio de que el sistema sui generis protege tanto a autores individuales como a la comunidad portadora; que puede ser algo dificultoso en su aplicación por el establecimiento de formalidades, como el registro de las expresiones para el uso, así como por la

la República y en los Tratados Internacionales de los que Ecuador es parte, se reconocen los derechos colectivos de los legítimos poseedores sobre sus conocimientos tradicionales. Estos derechos son imprescriptibles, inalienables e inembargables y forman parte de la identidad cultural de sus legítimos poseedores".

32 Cfr. Ley n.o 20 de 26 de junio de 2000, de Panamá, Régimen Especial de Propiedad Intelectual sobre los derechos colectivos de los pueblos indígenas, para la protección y defensa de su identidad cultural y de sus conocimientos tradicionales, art. 15: "Los derechos de uso y comercialización del arte, artesanías y otras manifestaciones culturales basadas en la tradicionalidad de los pueblos indígenas, deben regirse por el reglamento de uso de cada pueblo indígena, aprobado y registrado en la Digerpi o en la Dirección Nacional de Derecho de Autor del Ministerio de Educación, según el caso".

33 Cfr. Ley n. ${ }^{\circ} 20$, art. 4: "Se reconocen los derechos colectivos de los pueblos indígenas sobre sus instrumentos musicales, música, danzas o forma de ejecución, expresiones orales y escritas contenidos en sus tradiciones, que conforman su expresión histórica, cosmológica y cultural. La solicitud de registro de estos derechos colectivos se hará por los respectivos congresos generales o autoridades tradicionales indígenas, ante la Dirección General del Registro de la Propiedad Industrial del Ministerio de Comercio e Industrias [...] DigerPI, o ante la Dirección Nacional de Derecho de Autor del Ministerio de Educación, según corresponda, para su aprobación y registro”. Cfr. Código Orgánico de la Economía Social de los Conocimientos, Creatividad e Innovación del Ecuador, de 9 de diciembre de 2016, art. 522: "Forma de Protección. Se garantiza la protección efectiva y positiva de los conocimientos tradicionales contra el acceso, uso o aprovechamiento indebido por terceros no autorizados, expresada en los mecanismos de prevención, monitoreo y sanción que se generen en el reglamento que se expedirá para el efecto. El reconocimiento de los derechos colectivos de los legítimos poseedores sobre sus conocimientos tradicionales no está sujeto a formalidad o registro alguno para efectos de garantizar su protección, vigencia y ejercicio, ya que éste radica en la legitimidad del ámbito comunitario. Se promoverán mecanismos de fortalecimiento de capacidades locales sobre el derecho colectivo de los conocimientos tradicionales para su revitalización, promoción y protección”.

34 Espín Alba, Isabel, Contrato de edición literaria, Comares, Granada, 1994, pp. 106-111; Berrueco García, Adriana, "Arte indígena y derecho de autor", Revista Mexicana del Derecho de Autor, año IV, n.o 14, octubre-diciembre, 2004, p. 15.

35 Cfr. De Oliveira Ascensão, José de, "En torno al dominio público de pago y a la actividad de control de la administración en la experiencia portuguesa”, en ROGEL Vide, Carlos et al., La duración de la propiedad intelectual y las obras en dominio público, Reus, Madrid, pp. 285-287; así como De Román Pérez, Raquel, en Obras musicales, compositores, intérpretes y nuevas tecnologias, Reus, Madrid, 2003, pp. 514-519. 
indefinición en el tiempo del período de duración de la protección ${ }^{36}$. Sin embargo, ya hay experiencias notables bajo este sistema que expresan su valía ante el derecho de autor y su preferencia comunitaria, como son los casos de Panamá y Ecuador en América Latina.

\section{DOMINIO PÚBLICO}

Sobre la institución del dominio público respecto a las obras pertenecientes a la cultura popular tradicional en el derecho comparado, se manifiestan varias tendencias:

1. Muchos países reconocen en sus legislaciones que estas obras son de dominio público con determinadas semejanzas ${ }^{37}$, al coincidir unos en su regulación tradicional del dominio público sin referirse a obras de la cultura popular tradicional; y otros, que si las refieren, en diferencias particulares ${ }^{38}$ relacionadas con si se consideran además, patrimonio cultural. Algunos ${ }^{39}$ llegan a reconocer la variante pagante.

36 La variante sui generis posee, entre otras características particulares, el establecimiento de un tipo de protección indefinido en el tiempo, lo cual continúa dentro de la agenda del Comité Intergubernamental de la OMPI: "se está estudiando la posibilidad de establecer un tipo de protección que podría aplicarse indefinidamente a los conocimientos tradicionales y las expresiones culturales tradicionales que sean producto de la actividad intelectual, ya sea comunitaria o individual, y característicos de la identidad social y cultural y el patrimonio cultural de la comunidad". Revista de la OMPI, n. ${ }^{\circ} 121(\mathrm{~S})$, julio-agosto de 2005, p. 22. Ejemplos de legislaciones con este tipo de características son la Ley Tipo de Túnez sobre Derecho de Autor de 1976, la Ley n.o 20 de Panamá de 26 de junio de 2000 y su Decreto Ejecutivo n.o 12 de 20 de marzo de 2001, el Código Orgánico de la Economía Social de los Conocimientos, Creatividad e Innovación de Ecuador de 9 de diciembre de 2016 y su Reglamento General, Decreto Ejecutivo n. ${ }^{\circ}$ 1435, publicado en el Suplemento del Registro Oficial n. 9 de 7 de junio de 2017, así como la Ley Tipo del Pacífico Meridional para leyes nacionales de 2002. Cfr. Base de Datos de la ompi de Textos Legislativos de Propiedad Intelectual, disponible en: http://www.wipo.int. htm [consultada el 4 de diciembre de 2017].

37 Brasil, Jamaica, Costa Rica, El Salvador, Honduras y Uruguay tienen como elemento común que en su regulación tradicional del dominio público no se refieren expresamente a este tipo de obras o a expresiones culturales tradicionales pero, tal como hemos expuesto, quedan comprendidas en el dominio público pues así lo considera la doctrina y la jurisprudencia.

38 República Dominicana reconoce expresamente que las expresiones del folklore son de dominio público, al igual que Colombia y Perú, solo que estos dos últimos tienen, como diferencia de la primera y semejanza entre ellos, que al mismo tiempo pertenecen al patrimonio cultural; aspecto este último en el que coinciden con Bolivia: cfr. Ley de Derecho de Autor de Bolivia, n. 1322 de 13 de abril de 1992, título xi "Del Régimen Fiscal", capítulo I "Patrimonio Nacional y Dominio Público", art. 58: "Patrimonio Nacional es el régimen al que pasan las obras de autor boliviano que salen de la protección del derecho patrimonial privado, por cualquier causa; pertenecen al Patrimonio Nacional: a) Las obras folklóricas y de cultura tradicional de autor no conocido". Perú incluye en esta condición todas las otras obras en las que hayan expirado los derechos de autor. Venezuela, Dominica y México tienen en común que no se refieren a la condición de patrimonio cultural y, aunque tampoco expresamente a dominio público, se advierte la validez de este último, al vencer el plazo de protección para todas las obras. Cuba, por su parte, reconoce protección expresa a estas obras, pero al mismo tiempo establece de forma imprecisa que estas obras y expresiones han pasado al dominio público.

39 Uruguay y Bolivia coinciden en el establecimiento de una remuneración por utilización de todas las obras que caen en el dominio público, solo se diferencian en que Bolivia destina un $10 \%$ del recaudo por obras de Patrimonio Nacional al recopilador y un diez por ciento (10\%) a la comunidad de origen en caso de ser identificados. Cfr. 


\section{Otros las consideran parte del patrimonio cultural ${ }^{40}$.}

3. Un tercer grupo de países, aun cuando regulan el dominio público para todas las obras de forma expresa ${ }^{41}$, incluyendo las derivadas de expresiones del folklore que en su momento lleguen a pasar a esta condición, dejan fuera de este tratamiento las expresiones en sí, o bien, desde sus respectivas leyes de derecho de autor, introducen la posibilidad de un sistema sui generis de derechos colectivos mediante una legislación especial ${ }^{42}$, o lo hacen en sus actuales constituciones.

Ley de Derecho de Autor y Derechos Conexos de Uruguay, n. ${ }^{\circ} 17.616$ de 10 de enero de 2003, art. 42: "Cuando una obra caiga en el dominio público cualquier persona podrá explotarla con sujeción a las siguientes limitaciones: a) Deberá sujetarse a las tarifas que fije el Consejo de los Derechos de Autor. El Poder Ejecutivo, en la reglamentación de la ley, velará para que las tarifas que se adopten sean moderadas y generales para cada categoría de obras". Cfr. Ley de Derecho de Autor de Bolivia, n.o 1322 de 13 de abril de 1992, art. 60: "La utilización bajo cualquier forma o procedimiento de obras del Patrimonio Nacional y del dominio público será libre, pero quien lo haga comercialmente, pagará al Estado, de acuerdo con lo establecido en los reglamentos, una participación cuyo monto no será menor del diez por ciento (10\%) y no mayor del cincuenta por ciento (50\%) que el que se pague a los autores o sus causahabientes por utilización de obras similares sujetas al régimen privado de protección". Cfr. art. 61 ibíd.: "Los montos recaudados por concepto de utilización de obras del Patrimonio Nacional, se aplicarán únicamente al fomento y difusión de los valores culturales del país". Cfr. art. 62 ibíd.: "El Estado a través de la Dirección Nacional de Derechos de Autor reconocerá del porcentaje recaudado por obras de Patrimonio Nacional, un diez por ciento (10\%) al recopilador y un diez por ciento $(10 \%)$ a la comunidad de origen en caso de ser identificados".

40 Guatemala y Chile se diferencian del resto de las legislaciones y coinciden entre ellas en que marcadamente se considera que estas obras son patrimonio cultural del país. Respecto a Guatemala, cfr. art. 14: "Las expresiones de folclore pertenecen al patrimonio cultural del país y serán objeto de una legislación específica”. En relación con Chile, cfr. art. 11: "Pertenecen al patrimonio cultural común: a) las obras cuyo plazo de protección se haya extinguido; b) la obra de autor desconocido, incluyéndose las canciones, leyendas, danzas y las expresiones del acervo folklórico; c) las obras cuyos titulares renunciaron a la protección que otorga esta ley; d) las obras de autores extranjeros, domiciliados en el exterior, que no estén protegidos en la forma establecida en el artículo 2 (se refiere a los autores extranjeros domiciliados en Chile); y e) las obras que fueron expropiadas por el Estado, salvo que la ley indique un beneficiario".

41 Ecuador y Panamá. Cfr. Código Orgánico de la Economía Social de los Conocimientos, Creatividad e Innovación de Ecuador, de 9 de diciembre de 2016, art. 208: "Duración de los derechos patrimoniales en obras de comunidades, pueblos o nacionalidades. Para el caso de obras de comunidades, pueblos o nacionalidades a los que la Constitución reconoce derechos colectivos, en los que no se puede determinar autoría individual alguna, el plazo de protección será de setenta años contados a partir del registro de tal obra ante la autoridad nacional competente en materia de propiedad intelectual, la cual verificará entre otros requisitos, que la solicitud cuente con el consentimiento colectivo de las comunidades, pueblos o nacionalidades".

42 Cfr. Ley de Derecho de Autor y Derechos Conexos de Panamá, art. 9: "La protección reconocida en la presente Ley no alcanzará a los textos de las leyes, decretos, reglamentos oficiales, tratados públicos, decisiones judiciales y demás actos oficiales; ni a las expresiones genéricas del folclor, noticias del día, ni a los simples hechos y datos”. En esta ley no se explica la definición de expresiones genéricas del folclor, por lo que no sabemos con exactitud a qué se refiere el legislador; suponemos que son las diferentes a las reguladas en la ley, que son las de autor desconocido y por lo tanto son aquellas en que se identifique una comunidad portadora. En este caso estas expresiones se regirían por una legislación especial como la Ley n. ${ }^{\circ} 20$ de 26 de junio de 2000 de Panamá, Régimen Especial de Propiedad Intelectual sobre los Derechos Colectivos de los Pueblos Indígenas, disponible en: http://www.prodiversitas. bioetica.org/20pan.htm [consultado el 4 de diciembre de 2017]. 


\section{PROTECCIÓN INDIRECTA POR DERECHO CONEXOS}

Son varios ${ }^{43}$ los casos internacionales que demuestran cómo es posible, a partir de la protección dispensada a los artistas intérpretes o ejecutantes y a los productores de fonogramas, ya sea sobre sus interpretaciones o sus actividades de fijación en el fonograma, proteger también de forma indirecta expresiones culturales tradicionales.

Con independencia de las posibilidades que brinda este sistema de derechos conexos, contra él atenta el hecho de que no todas las expresiones culturales tradicionales "caben" en su protección, como es el caso de las producciones artesanales tradicionales como dibujos, pinturas, tallas, esculturas, cerámica, terracota, mosaico, artesanía en madera, metalistería, joyería, textiles, alfombras; pues la protección solo cubre "interpretaciones o ejecuciones", en el caso de los artistas intérpretes o ejecutantes, en virtud del Tratado de la OMPI sobre Interpretación o Ejecución y Fonogramas, adoptado en Ginebra el 20 de diciembre de 1996. Este tratado recoge expresamente en la definición de artistas intérpretes o ejecutantes a los que interpreten o ejecuten expresiones del folklore, esto en su artículo 2.a $)^{44}$.

El tratamiento de los derechos conexos aparece recogido en 17 de las legislaciones estudiadas; solo Cuba no reconoce derechos conexos por no establecer esta protección en su legislación autoral. Se asemejan aquellas, en su regulación, en el hecho de no hacer mención expresa a obras o expresiones culturales tradicionales; solo Guatemala se diferencia de todas en que sí las refiere a quienes las interpreten o ejecuten ${ }^{45}$.

43 Los dos casos presentados contra el líder del grupo alemán "Enigma”, Michael Cretu, en los años 1994 y 1998. En el primero fue emplazado por los intérpretes del coro de la ciudad de Múnich "Kapelle Antiqua” y su discográfica, Polydor, por haber infringido los "derechos morales" sobre sus interpretaciones de cantos gregorianos contenidas en grabaciones, al sacarlas de contexto para usarlas en los temas "Sadness (Part I)" у "Mea Culpa", incluidas en su álbum debut “мсмхс a.D.". Cfr. Kapelle Antiqua v. Michael Cretu (Enigma), 1994, en Riley, Angela "Recovering Collectivity, Groups Rights to Intellectual Property in Indigenous Communities”, 18 Cardozo Arts and Entertainment Law Journal, 2000, p. 175, disponible en: http://U.K.Westlaw.com [consultado el 4 de diciembre de 2017]. Además, cfr.: http://new.taringa.net/posts/musica/6341801/Enigma_-Discografia--hotfile-actualizada.html [consultado en igual fecha]. En 1998, el matrimonio Lifvon Guo e Igay Guo, de la tribu taiwanesa de los ami, demandaron a Michael por no acreditar sus grabaciones vocales de una canción tribal, tomadas para usarlas en el famoso tema "Return to innocence". El caso fue resuelto a favor de los demandantes, con la consiguiente obligación de Michael Cretu de compensar a los afectados y acreditar legalmente el origen del material utilizado. Lifvon Guo. v. Michael Cretu (Enigma), 1998. Cfr. Riley, ob. cit., p. 18.

44 Texto del propio tratado. Cfr. también el documento de la ompi que refiere este particular: CRNR/DC/95, disponible en: http://www.wipo.int [consultado el 4 de diciembre de 2017].

45 Cfr. Ley de Derecho de Autor y Derechos Conexos, de 21 de mayo de 1998, art. 4: "Para efectos de esta ley se entiende por:

"Artista intérprete o ejecutante: Todo actor, cantante, músico, bailarín u otra persona que represente un papel, cante, recite, declame, interprete o ejecute en cualquier forma obras literarias o artísticas o expresiones de folclore". 


\section{CONCLUSIONES}

El derecho de autor y los derechos conexos constituyen una de las vías de protección de la cultura popular tradicional, que aunque no es la única, otorga protección positiva para las obras literarias y artísticas, creadas por autores que no se hayan identificado, que se presuman nacionales del país y se transmitan de generación en generación, de manera que reflejen las expectativas artísticas o literarias tradicionales de una comunidad; así como también para las obras contemporáneas creadas por autores actuales con técnicas tradicionales, y para las obras derivadas basadas en obras preexistentes de la cultura popular tradicional. De igual forma, protege las expresiones culturales de forma indirecta en la persona de los artistas intérpretes o ejecutantes, cuando realizan interpretaciones o ejecuciones de expresiones culturales tradicionales que no califican como obras, así como cuando estas expresiones quedan incorporadas en fonogramas o en emisiones de radiodifusión. En cuanto a la autoría, pueden ser obras simples u obras en colaboración o colectivas, en dependencia del caso de que se trate, ya que cabe la posibilidad de que haya una pluralidad de autores pertenecientes o no a la comunidad donde se ha cultivado la obra.

Cuando no se identifica el autor de obras de la cultura popular tradicional, puede reconocerse la titularidad derivada respecto a esas obras a la comunidad portadora, si se identificase, o en su defecto, la autoridad competente que se disponga podrá actuar en defensa de la obra. El grupo social que ha cultivado y desarrollado la obra de autor no identificado adquirirá la condición de titular derivado del derecho de autor.

En la actualidad se ha desarrollado un sistema sui generis de protección con el que se identifican en mayor medida determinadas comunidades para la protección de sus derechos intelectuales. Este sistema difiere del de derecho de autor y lentamente ha ido estableciéndose tanto por la doctrina como por la práctica cultural y la legislación nacional. Este sistema opera sobre la base del reconocimiento de derechos colectivos y del pluralismo jurídico latinoamericano, al ratificar la esencia comunitaria de estas obras y expresiones y la titularidad de los derechos en cabeza de las propias comunidades portadoras. Varias leyes nacionales de los países estudiados apuestan por este sistema, como es el caso de la venezolana (solo en el texto constitucional), la panameña y la ecuatoriana.

La recepción normativa de la protección de las obras de la cultura popular tradicional en las leyes de derecho de autor de América Latina y el Caribe es diversa; se acogen este tipo de obras en algunas legislaciones y en otras no, utilizando distintas denominaciones en su regulación, donde prima que son obras de autores no identificados relacionados con una comunidad.

Todas las legislaciones consultadas protegen las obras derivadas de la cultura popular tradicional; solo Panamá y Ecuador se diferencian marcadamente, esto por considerar que las no derivadas constituyen objeto de derechos colectivos de propiedad intelectual, posibilidad a la que también se abre Bolivia. 
Todos los países cuyas legislaciones se examinaron consideran que estas obras son de dominio público, a excepción de Bolivia, Guatemala y Chile por considerarlas patrimonio cultural. Todos, con excepción de Cuba, dejan abierta la posibilidad de protección indirecta por la vía derechos conexos, y solo Guatemala menciona expresamente este tipo de protección.

\section{REFERENCIAS}

"Propuesta de un instrumento internacional para la protección del folklore", Comité Intergubernamental de Derecho de Autor, Duodécima Reunión de la Organización Mundial de la Propiedad Intelectual, París, diciembre de 1973, IGC/xiI/12, disponible en: http://www.wipo.int [consultado el 1 de mayo de 2017].

"Protección de los conocimientos tradicionales y el folklore", documento del Consejo de los Aspectos de los Derechos de Propiedad Intelectual relacionados con el Comercio de la Organización Mundial del Comercio, IP/c/w/370/Rev.1, 9 de marzo de 2006, disponible en: www.wto.org [consultado 25 de agosto 2017].

Acuerdo de Bangui por el que se crea la Organización Africana de la Propiedad Intelectual (OAPI), revisado en 1999, en Base de Datos de la OMPI de Textos Legislativos de Propiedad Intelectual, disponible en: http://www.wipo.int.htm [consultado el 4 de diciembre de 2017].

Base de Datos de la ompr de Textos Legislativos de Propiedad Intelectual, disponible en: http://www.wipo.int.htm [consultado el 4 de diciembre de 2017].

Berrueco García, Adriana, "Arte indígena y derecho de autor", Revista Mexicana del Derecho de Autor, año IV, n. ${ }^{\circ}$ 14, octubre-diciembre, 2004.

Carracedo González, Clara Marvilia, "Medios jurídicos para la protección de las artesanías en la legislación cubana de propiedad intelectual: ventajas de la protección acumulada", Documento OMPI-CCI/DA/HAV/01/4, $21 \mathrm{de}$ febrero de 2001, disponible en: www.wipo.int/.../omPI_CCI.../OMPI_CCI_ DA_HAV_01_4_S.pdf [consultado el 27 de febrero de 2017].

Código Orgánico de la Economía Social de los Conocimientos, Creatividad e Innovación del Ecuador, de 9 de diciembre de 2016, y su Reglamento General, Decreto Ejecutivo n. ${ }^{\circ}$ 1435, Suplemento del Registro Oficial n. ${ }^{\circ} 9$ de 7 de junio de 2017, disponible en: http://www.wipo.int/edocs/lexdocs/laws/es/ec/ ec075es.pdf [consultado el 4 de diciembre de 2017].

Colección de Leyes Nacionales sobre Derecho de Autor, disponible en: http://portal. unesco.org/culture/es/ev.php-URL_ID=I4076\&URL_DO=DO_TOPIC\&URL_SECTION=201.html [consultada el 4 de diciembre de 2017].

Constitución de la República Bolivariana de Venezuela. Publicada en Gaceta Oficial del jueves 30 de diciembre de 1999, n. ${ }^{\circ} 36.860$.

D'Ormesson-Kersaint, Blanche, "La protection de oeuvres du domaine public", RIDA, 1983. 
De Oliveira Ascensão, José de, "En torno al dominio público de pago y a la actividad de control de la administración en la experiencia portuguesa", en Rogel Vide, Carlos et al., La duración de la propiedad intelectual y las obras en dominio público, Reus, Madrid, pp. 285-287.

De Román Pérez, Raquel, Obras musicales, compositores, intérpretes y nuevas tecnologías, Reus, Madrid, 2003.

Decreto n. ${ }^{\circ}$ 141-93, Ley de Derecho de Autor y Derechos Conexos, de 8 de diciembre de 1993, de Honduras, en Base de Datos de Leyes Nacionales sobre Derechos de Autor de la Unesco, disponible en: http://portal.unesco.org/ culture/es/ev.phpURL_ID=I4O76\&URL_DO=DO_TOPIC\&URL_SECTION=201.html [consultada el 4 de diciembre de 2017].

Disposiciones revisadas para la protección de las expresiones culturales tradicionales/ expresiones del folclore. Objetivos políticos y principios fundamentales, OMPI, Comité Intergubernamental sobre Propiedad Intelectual y Recursos Genéticos, Conocimientos Tradicionales y Folclore, Decimosexta Sesión, Ginebra, 3 al 7 de mayo de 2010, Documento ompI WiPo/GrTkf/IC/16/4 Prov, 22 de enero de 2010, disponible en: http://www.wipo.int/tk/es/consultations/dra$\mathrm{ft} \_$provisions/draft_provisions.html [consultado el 4 de diciembre de 2017].

Documento "La artesanía: identidad y patrimonio cultural de los pueblos", disponible en: www.lacult.org/docc/Documento_Trinidad.doc [consultado el 27 de febrero de 2012].

Espín Alba, Isabel, "Las obras procedentes de la cultura popular y el derecho de autor en España. El artículo 10 y concordantes de la Ley de Propiedad Intelectual. Las obras de arte aplicadas", en Cultura popular $y$ propiedad intelectual, Valdés Díaz, Caridad y Rogel Vide, Carlos (dirs.), Martín, Abel (coord.) y Anguita, Luis (supervisor de textos), Reus, Madrid, 2011.

Espín Alba, Isabel, Contrato de edición literaria, Comares, Granada, 1994, pp. 106-111.

Fernández Bulté, Julio, Teoría del Estado y el derecho. Teoría del derecho, Félix Varela, La Habana, 2001.

Frómeta Lores, Manuel; Pardo Fernández, Alfredo y Lemes Fernández, Lino, Para un análisis del concepto cultura, El Mar y La Montaña, Guantánamo, 2002.

Garrote Fernández-Díez, I., "El patrimonio inmaterial y los derechos de propiedad intelectual”, en Patrimonio Cultural de España, n. ${ }^{\circ}$ 0, 2009.

Glosario de términos de la Unesco, disponible en: http://www.unesco.org [consultado 1 de mayo de 2011].

GutiérRez, ERICK, La Iiterculturalidad en el Estado venezolano: los derechos humanos de los pueblos y comunidades indígenas, Defensoría del Pueblo y Fundación Juan Vives Suriá, Caracas, 2011.

HaRvey, David, "El nuevo imperialismo, acumulación por desposesión", en Socialist Register, 114, 2004. 
Información acerca del Informe del Relator Especial en el Estudio de la Propiedad Cultural e Intelectual de Pueblos Indigenas, Naciones Unidas escor, Human Rights Comm., Sub-Comm. en la Prevención de Discriminación y Protección de Minorías, Naciones Unidas, Grupo de Trabajo en Poblaciones Indígenas, 11 Sess., Artículo 7 de la Agenda Provisional, p. 3, Naciones Unidas Doc. E/ CN.4/Sub.2/AC.4/1993/9 (1993), disponible en: http://www.un.org/esa/ socdev/unpfii/en/second.html [consultado el 2 de mayo de 2016].

Informe relativo al Estudio Preliminar sobre la conveniencia de reglamentar en el ámbito internacional la protección de la cultura tradicional y popular mediante un nuevo instrumento normativo, Organización de las Naciones Unidas para la Educación, la Ciencia y la Cultura, 161. a Reunión, 161 EX/15, París, 16 de mayo de 2001, disponible en: www.unesco.org [consultado el 17 de diciembre de 2009].

Kroeber A., L. y Kluckhohn C., Culture, A Critical Review of Concepts and Definitions, Cambridge, Mass., 1952.

Kuruk, PAul, "El derecho consuetudinario en África y la protección del folklore", en Boletín de Derecho de Autor, Unesco, vol. xxxvi, n.o 2, 2002.

Lipszyc, Delia, Derecho de autor y derechos conexos, Unesco, Cerlalc, Zavalía y Editorial "Félix Varela”, La Habana, 1998.

López Segrera, Francisco, "Globalización, cultura y desarrollo", en Honda, Revista de la Sociedad Cultural José Martí, n. ${ }^{\circ}$ 2, año 1, 2000.

Lucas-Schloetter, Agnes, "The Tunis Model Law on Copyright (wipo/Unesco, 1976), Section 4, Folklore”, en Von Lewinsky, Silke, Indigenous heritage and intellectual property, genetic resources, traditional knowledge and folklore, Kluwer Law International, The Hague, 2004.

Pérez Peña, Óscar Alberto, "Propiedad intelectual y patrimonio cultural: protección jurídica a la cultura popular tradicional, con especial referencia a Cuba", Revista Propiedad Intelectual, Universidad de los Andes (Venezuela), año $\mathrm{x}, \mathrm{n} .{ }^{\circ}$ 14, diciembre 2011.

Pérez Peña, Óscar Alberto, Protección de las obras de la cultura popular tradicional por el derecho de autor: especial referencia a Cuba, tesis presentada para aspirar al título de doctor en Ciencias Jurídicas de la Universidad de La Habana, realizada bajo la tutela de la Dra. Caridad Valdés Díaz, Editorial Universitaria, 2013.

Propiedad intelectual y conocimientos tradicionales, folleto n. ${ }^{\circ} 2$, Organización Mundial de la Propiedad Intelectual, documento n. ${ }^{\circ}$ 920(S).

Propiedad intelectual. Biblioteca de legislación, Aranzadi, 2010.

Proteja y promueva su cultura. Guía práctica sobre la propiedad intelectual para los pueblos indigenas y las comunidades locales, OMPI, Ginebra, 2017.

Proyecto de disposiciones sobre las expresiones culturales tradicionales/folclore y los conocimientos tradicionales, disponible en: http://www.wipo.int/tk/es/consultations/ draft_provisions/draft_provisions.html [consultado el 4 de diciembre de 2017]. 
Riley, Angela, "Recovering collectivity, groups rights to intellectual property in indigenous communities", 18 Cardozo Arts and Entertainment Law Journal, 2000, disponible en: http://U.K.Westlaw.com [consultado el 4 de diciembre de 2017].

Soto Granados, Margarita, "El derecho de autor en Cuba: casos destacados de la práctica jurídica", Biblioteca Jurídica Virtual del Instituto de Investigaciones Jurídicas de la UNAM, disponible en: http: //www.juridicas.unam.mx [consultado en agosto de 2017].

Stoll, Peter-Tobias y Von Hahn, Anja, "Part II. Indigenous peoples, indigenous knowledge and indigenous resources in International Law", en Von LEWINSKI, SiLke, Indigenous Heritage and Intellectual Property, Kluwer Law International, The Netherlands, 2004.

Vicente Blanco, Dámaso Javier, "Protección de la cultura popular y entidades de gestión colectiva: ¿apropiación de bienes comunes y enriquecimiento sin causa?", presentado en Jornadas Internacionales "Arte y Derecho", Azul, Provincia de Buenos Aires, 15 a 18 de noviembre de 2012, sin publicar.

Wendland B. Wend, "Patrimonio inmaterial y propiedad intelectual: retos y perspectivas", Revista Museum Internacional.

WiesSNER, SiEgfried, "Rights and status of indigenous peoples: A global comparative and international legal analysis", Harvard Human Rights Journal, 12, 1999.

Wolfrum, Rüdiger, "La protección de los pueblos indígenas en el derecho internacional", Heidelberg Internacional Journal, 59, 1999.

Zerda Sarmiento, Álvaro y Forero Pineda, Clemente, "Los derechos de propiedad intelectual sobre los conocimientos de las comunidades étnicas", disponible en: http://www.cerlalc.org [consultado el 25 de agosto de 2017].

RESOLUCIONES JUDICIALES CONSULTADAS

Sentencia 168, de 30 de junio de 2006, Administrativo, Sala Segunda de lo Civil y Administrativo del Tribunal Provincial Popular de Ciudad de La Habana.

Sentencia 402, de 29 de diciembre de 2009, Administrativo, Sala Primera de lo Civil y Administrativo del Tribunal Provincial Popular de Ciudad de La Habana.

Sentencia 451, de 28 de diciembre de 2004, Administrativo, Sala Segunda de lo Civil y Administrativo del Tribunal Provincial Popular de Ciudad de La Habana. Sentencia 85, de 30 de septiembre de 2003, Civil, Sala Primera de lo Civil y Administrativo del Tribunal Provincial Popular de Ciudad de La Habana, exp. 63 de 2003.

Sentencia Corte Civil, Condado de New York, Palmieri vs. Estefan, en Soto Granados, Margarita, "Oye mi canto. Palmieri vs. Estefan”, en Plagios y desconciertos, parte I, Ediciones Digitales Mare Nostrum, México D.F., 1997.

Sentencia Corte Federal de Australia, Bulun Bulun v. R\& T Textiles Pty Ltd. (1998) 86 F.C.R. 244-246, disponible en: http://U.K.Westlaw.com/Find/Default. 
wl? rs=WLUK.1.0\&vr=20\&.DB=3125\&Findtype $=y \&$ ReferencePositionTy pe $=S \&$ SerialNum $=0327548084 \&$ ReferencePosition $=246$ [consultado el 15 de marzo de 2017].

Sentencia Corte Federal de Australia, Milpurruru v. Indofurn Pty Ltd., en Janke, Ms. Terri, Minding Culture: Case Studies on Intellectual Property and Traditional Cultural Expressions, World Intellectual Property Organization, wiPO Publication n. ${ }^{\circ} 781$ (E), Geneva, 2003,.

Sentencia Corte Federal de Australia, Yumbulul v. Reserve Bank of Australia, (1991) 21 I.P.R. 481, 490 (Austl.), en Haight Farley, Christine, "Protecting folklore of indigenous peoples is intellectual property the answer?", Connecticut Law Review, 1997, disponible en: http://U.K.Westlaw.com/30.Conn.L.Rev.1 [consultado el 15 de marzo de 2017].

Sentencia del Tribunal de Gran Instancia de París, 15 de abril de 1954.

Sentencia n. ${ }^{\circ} 1375$, de 30 de diciembre de 2008, Sala de lo Civil y de lo Administrativo del Tribunal Supremo Popular, recurso de casación en materia administrativa.

Sentencia n. ${ }^{\circ}$ 20, de 30 de noviembre de 2011, Sala de lo Civil y de lo Administrativo del Tribunal Supremo Popular, proceso de revisión en materia administrativa.

Sentencia n. ${ }^{\circ}$ 95, de 29 de octubre de 2003, Civil, Sala Primera de lo Civil y Administrativo del Tribunal Provincial Popular de Ciudad de La Habana.

Sentencia, Kapelle Antiqua. v. Michael Cretu (enigma), 1994, en Riley, Angela, "Recovering collectivity, groups rights to intellectual property in indigenous communities", 18 Cardozo Arts and Entertainment Law Journal, 2000, disponible en: http://U.K.Westlaw.com [consultado el 15 de marzo de 2017].

Sentencia, Lifvon Guo. v. Michael Cretu (enigma), 1998, Riley, Angela, "Recovering collectivity, groups rights to intellectual property in indigenous communities", 18 Cardozo Arts and Entertainment Law Journal, 2000, disponible en: http://U.K.Westlaw.com [consultado el 15 de marzo de 2017]. 